nasal and oral breathing while the oronasal mask was used. It is possible that this is a major determinant of how the oronasal interface will impact on the distribution of pressures in the nasal and oral segments. There is evidence that upper airway resistance during sleep and the propensity to obstructive sleep apnoea are significantly lower while breathing nasally rather than orally [7].

TEO et al. [3] have recently reported the first randomised trial that compared CPAP titration with nasal and oronasal masks in patients with newly diagnosed OSA. While the CPAP pressures achieved by nasal and oronasal interfaces was similar $(\sim 11$ $\left.\mathrm{cmH}_{2} \mathrm{O}\right)$ the AHI was significantly lower on nasal mask $(5.3 \pm 3.4$ versus $11.0 \pm 10.4$ events per $h$, respectively; $\mathrm{p}=0.01$ ). Moreover, the high AHI standard deviation while on oronasal mask indicates a wide effectiveness variability. In the study of TEO et al. [3] the use of oronasal mask was also associated with worse sleep quality, higher air leak and poorer patient satisfaction. We speculate that the observed mechanisms in our patient may help to explain why several patients are not effectively treated while on oronasal CPAP. These mechanisms may contribute to higher air leak and poorer treatment satisfaction.

In conclusion, our case report is in line with recent studies suggesting that CPAP delivered by oronasal interface may not be effective in a subgroup of patients with OSA [3,4]. Our case report suggests that $\mathrm{CPAP}$ delivered through an oronasal interface may push the tongue backwards in some patients. Therefore, a nasal mask should be preferred as the first option as a CPAP interface. Patients on an oronasal mask should be carefully followed. The low compliance to CPAP when an oronasal interface is used may be partially explained by suboptimal therapeutic effectiveness.
Fabíola Schorr, Pedro R. Genta, Marcelo G. Gregório, Naury J. Danzi-Soares and Geraldo Lorenzi-Filho

Sleep Laboratory, Pulmonary Division, Heart Institute (InCor), University of São Paulo School Medicine, São Paulo, Brazil.

Correspondence: G. Lorenzi-Filho, University of São Paulo, Av. Dr. Eneas de Carvalho, Aguiar 44, São Paulo, 05403-000, Brazil. E-mail: geraldo.lorenzi@incor.usp.br

Statement of Interest: None declared.

\section{REFERENCES}

1 Sullivan CE, Issa FG, Berthon-Jones M, et al. Reversal of obstructive sleep apnoea by continuous positive airway pressure applied through the nares. Lancet 1981; 1: 862-865.

2 Mortimore IL, Whittle AT, Douglas NJ. Comparison of nose and face mask CPAP therapy for sleep apnoea. Thorax 1998; 53: 290-292.

3 Teo M, Amis T, Lee S, et al. Equivalence of nasal and oronasal masks during initial CPAP titration for obstructive sleep apnea syndrome. Sleep 2011; 34: 951-955.

4 Kaminska M, Montpetit A, Mathieu A, et al. Differences in effectiveness of nasal and facial CPAP masks in obstructive sleep apnea, and effect of mandibular stabilization. Sleep 2010; 33: Suppl., A158.

5 Gregório MG, Jacomelli M, Inoue D, et al. Comparison of full versus short induced-sleep polysomnography for the diagnosis of sleep apnea. Laryngoscope 2011; 121: 1098-1103.

6 Smith PL, Wise RA, Gold AR, et al. Upper airway pressure-flow relationships in obstructive sleep apnea. J Appl Physiol 1988; 64: 789-795.

7 Fitzpatrick MF, McLean H, Urton AM, et al. Effect of nasal or oral breathing route on upper airway resistance during sleep. Eur Respir J 2003; 22: 827-832.

DOI: $10.1183 / 09031936.0014511$

\title{
Combined pulmonary fibrosis and emphysema associated with microscopic polyangiitis
}

\section{To the Editors:}

Microscopic polyangiitis (MPA) is a necrotising multiorgan vasculitis associated with a variety of circulating autoantibodies, such as anti-neutrophil cytoplasm antibodies (ANCAs) against myeloperoxidase (MPO) [1]. Typical and most common pulmonary involvement comprises of alveolar haemorrhage secondary to pulmonary capillaritis as well as interstitial lung fibrosis [2] and progressive obstructive lung disease [1, 3, 4].

The combination of pulmonary fibrosis and emphysema (CPFE) is a recently defined syndrome, encompassing a distinct radiology, revealing both upper-lobe emphysema and lower-lobe fibrosis on high-resolution computed tomography (HRCT) of the chest, as well as lung function profile, with apparently preserved lung volumes contrasting with disproportionally impaired gas exchange, as assessed by reduced diffusing capacity of the lung for carbon monoxide $[5,6]$. CPFE has been recently described in the context of connective tissue diseases [7]. Nevertheless, it is still debatable whether CPFE represents a distinct syndrome or it is just a phenotype of pulmonary fibrosis with coincidental emphysema. Here, we describe for the first time, in a male patient, a novel type of pulmonary manifestation of MPA, the combination of pulmonary fibrosis and emphysema.

In 2008, an 80-yr-old Greek-Caucasian male, heavy ex-smoker (80 pack-yrs), ex-farmer and coal worker with a history of idiopathic pulmonary fibrosis, based on the absence of other underlying conditions and the presence of a histopathological and radiological pattern of usual interstitial pneumonia combined with upper-lobe emphysema (fig. $1 \mathrm{a}$ and b) since 2005, was referred to the emergency department of the University Hospital of Alexandroupolis (Alexandroupolis, Greece) due to 

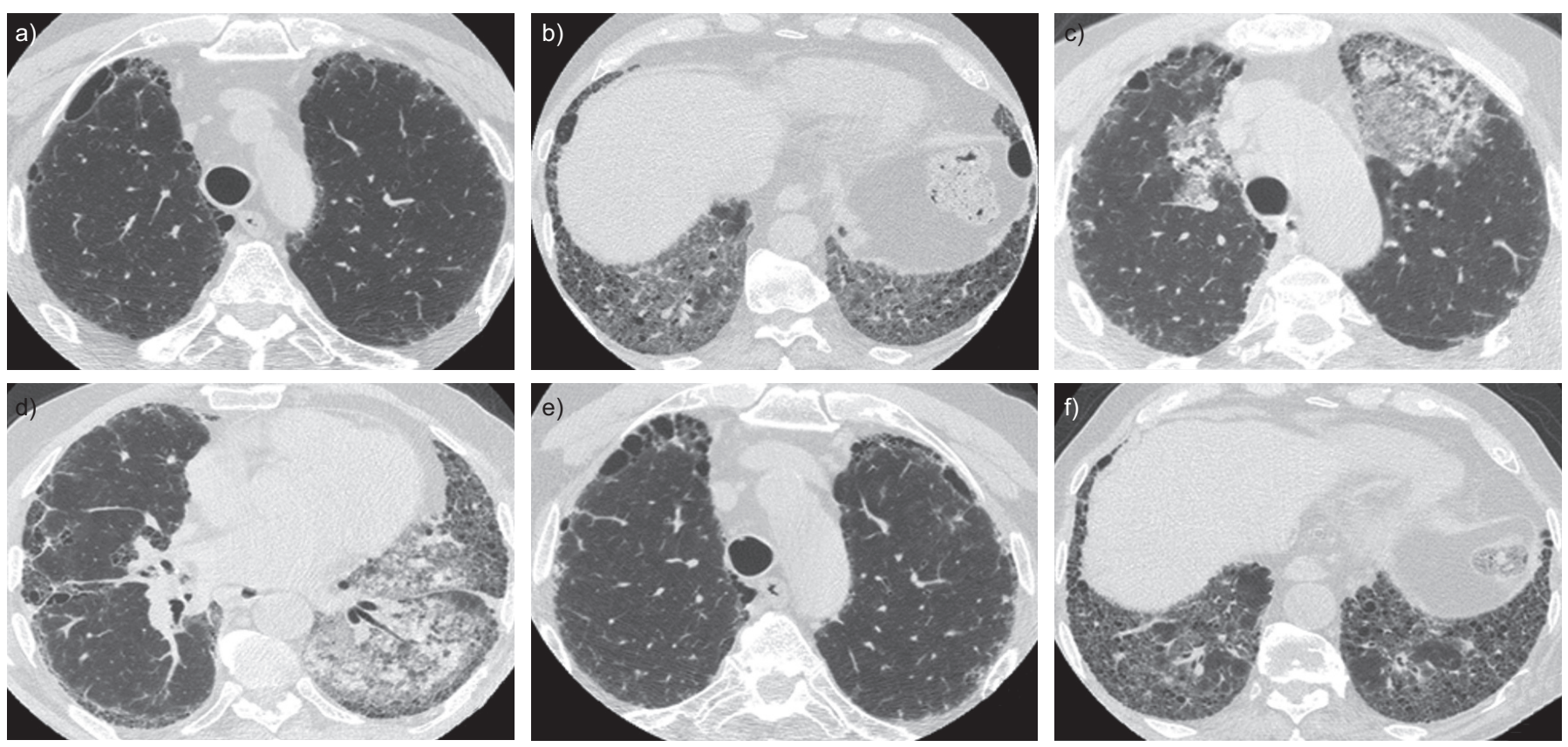

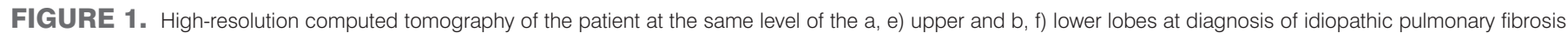

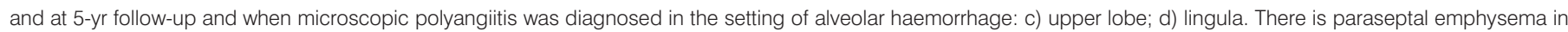

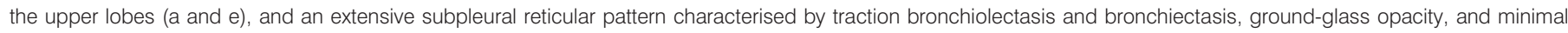

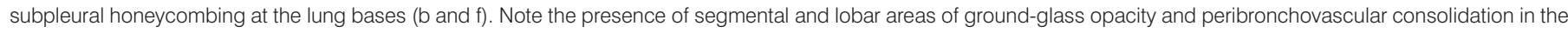
c) right and left upper lobes and d) lingula consistent with alveolar haemorrhage.

haemoptysis, progressive breathlessness on mild exertion and low-grade fever $\left(37.5^{\circ} \mathrm{C}\right)$ for the previous 4 days.

On physical examination he was in extremis, with tachypnoea (respiratory rate 24 breaths $\cdot \mathrm{min}^{-1}$ ) and tachycardia (heart rate 100 beats $\left.\cdot \min ^{-1}\right)$. Arterial blood gas analysis demonstrated respiratory failure (arterial oxygen tension $55 \mathrm{mmHg}$, artierial carbon dioxide tension $39 \mathrm{mmHg}$ and $\mathrm{pH} 7.42$ while breathing room air). He also had clubbing with no skin lesions, cervical lymphadenopathy or joint swelling. Auscultation of the lungs revealed bibasal inspiratory crackles. The rest of the physical examination was unremarkable. On admission, laboratory findings revealed an elevated erythrocyte sedimentation rate $\left(65 \mathrm{~mm} \cdot \mathrm{h}^{-1}\right)$, with mild leukocytosis $\left(1.124 \times 10^{4}\right.$ white blood cells per $\mu \mathrm{L})$, anaemia with a significant decline of the haematocrit $(\mathrm{Ht})$ levels from baseline values ( $\mathrm{Ht} 42.5 \%$, haemoglobin $(\mathrm{Hb})$ $14.1 \mathrm{~g} \cdot \mathrm{dL}^{-1}$ versus $\left.\mathrm{Ht} 28.5 \%, \mathrm{Hb} 9.5 \mathrm{~g} \cdot \mathrm{dL}^{-1}\right)$, elevated C-reactive protein $\left(12.86 \mathrm{mg} \cdot \mathrm{dL}^{-1}\right)$ abnormal serum creatinine concentrations $\left(116 \mu \mathrm{mol} \cdot \mathrm{L}^{-1}\right)$, elevated $24-\mathrm{h}$ urine protein levels $\left(1,400 \mathrm{mg} \cdot \mathrm{dL}^{-1}\right)$ and haematuria with red blood cell renal casts in microscopic urine analysis. His tuberculin skin test was negative. Functional assessment showed a moderate restrictive pattern that was significantly deteriorated compared with baseline values (table 1). Chest radiography (not shown) followed by HRCT revealed diffuse ground-glass opacities and areas of peribronchovascular consolidation consistent with alveolar haemorrhage (fig. 1c and d). On day 2, flexible bronchoscopy followed by bronchoalveolar lavage (BAL) was undertaken and revealed findings compatible with alveolar haemorrhage, with a red macroscopic appearance and $>40 \%$ siderophages. No endobronchial lesion was detected. BAL specimens were smear and culture negative for common bacteria and acid-fast bacilli. Immunological testing revealed increased titres of antinuclear antibody (1/160), and anti-MPO antibodies estimated by ELISA (14 ELISA units (EU) per mL, normal range $<9.0 \mathrm{EU} \cdot \mathrm{mL}^{-1}$ ) and immunofluorescence analysis (perinuclear pattern ANCA 1/20). His immunoglobulin levels were slightly elevated $3.1 \mathrm{mg} \cdot \mathrm{dL}^{-1}$ (normal range $2.5-3.0 \mathrm{mg} \cdot \mathrm{dL}^{-1}$ ). While the patient was experiencing a rapid deterioration of his renal function (serum creatinine levels $255 \mu \mathrm{mol} \cdot \mathrm{L}^{-1}$ ), he underwent renal biopsy showing necrotising glomerulonephritis and capillaritis, which constitute evidence compatible with necrotising MPA.

The patient was commenced on 3-day pulses of $1 \mathrm{~g}$ methylprednisolone followed by $60 \mathrm{mg}$ of oral cyclophosphamide per day, with improvement of his renal (serum creatinine levels 177 $\left.\mu \mathrm{mol} \cdot \mathrm{L}^{-1}\right)$ and general clinical condition. The patient was discharged on day 21 with $\mathrm{N}$-acetylcysteine $(1,800 \mathrm{mg}$ daily) coupled with $60 \mathrm{mg}$ of oral cyclophosphamide per day for 6 months and $60 \mathrm{mg}$ oral prednisolone per day for 6 months, gradual tapering (overall 7 months). 2 yrs after treatment completion, his serum creatinine levels dropped to $88 \mu \mathrm{mol} \cdot \mathrm{L}^{-1}$, his 24-h urine protein levels were within the normal range and his anti-MPO levels were undetectable. A stabilisation of lung involvement, as assessed by both functional (table 1) and radiological status (fig. 1e and f) was also reported.

CPFE occurring in the context of autoimmune disorders, such as MPA, may provide a common pathogenetic mechanism for both emphysema and pulmonary fibrosis. Recent data give credence to the view that circulating neutrophils, through exogenous stimulation such as cigarette smoke and/or occupational 


\begin{tabular}{|c|c|c|c|}
\hline \multirow[t]{3}{*}{ TABLE 1} & \multicolumn{3}{|c|}{$\begin{array}{l}\text { Summary of pulmonary function tests, } 6 \text {-min } \\
\text { walk distance }(6 \mathrm{MWD}) \text {, systolic pulmonary artery } \\
\text { pressure ( } \mathrm{SP} \text { pa) and arterial blood gases }\end{array}$} \\
\hline & \multicolumn{3}{|c|}{ Time after MPA diagnosis } \\
\hline & -12 months & 0 months & 36 months \\
\hline FEV $1 \%$ pred & 69.2 & 59.6 & 60.9 \\
\hline FVC \% pred & 70.1 & 63.6 & 67.7 \\
\hline FEV $1 / F V C$ & 73.7 & 70.8 & 66.2 \\
\hline FEF25-75\% \%pred & 44 & 40 & 33 \\
\hline TLC \% pred & 73 & 58.5 & 53.3 \\
\hline DL,Co \%pred & 43.4 & 25.7 & 30.2 \\
\hline 6MWD m & 380 & NA & 370 \\
\hline $\mathbf{s P p a}{ }^{\#} \mathbf{m m H g}$ & 25 & 35 & 35 \\
\hline $\mathrm{Pa}, \mathrm{O}_{2} \mathrm{mmHg}$ & 66 & 55 & 60 \\
\hline $\mathrm{Pa}, \mathrm{CO}_{2} \mathrm{mmHg}$ & 40 & 39 & 46 \\
\hline
\end{tabular}

MPA: microscopic polyangiitis; FEV1: forced expiratory volume in $1 \mathrm{~s}$; \% pred: $\%$ predicted; FVC: forced vital capacity; FEF25-75\%: forced expiratory flow at $25-75 \%$ of FVC; TLC: total lung capacity; $D L, C O$ : diffusing capacity of the lung for carbon monoxide; $\mathrm{Pa}_{\mathrm{O}} \mathrm{O}_{2}$ : arterial oxygen tension; $\mathrm{Pa}_{1} \mathrm{CO}_{2}$ : arterial carbon dioxide tension; NA: not available. ${ }^{*}$ : measured by echocardiography.

exposure, become primed and express MPO on their surfaces [8]. Increased circulating levels of MPO on activated neutrophils for prolonged periods of time, especially in heavy smokers, may lead to loss of immune tolerance and acceleration of autoimmunity phenomena, including production of MPO-ANCA. The latter may promote degranulation of reactive oxygen species located within the neutrophilic cytoplasmic domain, resulting in an uncontrolled oxidative burst within the pulmonary interstitium that could promote fibroblast proliferation as well as alveolar epithelial and endothelial cell apoptosis, leading to fibrosis and emphysema development [9].

In line with this hypothesis, it is conceivable to speculate that in our case study, MPA followed an inconspicuous clinical course with low titres of MPO antibodies, undetectable using the conventional immunoassays but enough to trigger the pathogenetic cascade of emphysema and fibrosis. The latter became clinically prominent when MPO antibodies reached a critical level sufficient to cause renal dysfunction, alveolar haemorrhage and progression of fibrosis and emphysema, as indicated by clinical, functional and radiological deterioration.
Larger studies screening, on a repetitive basis, patients with CPFE for circulating autoantibodies are sorely needed to exclude the possibility of clinically inconspicuous autoimmune disorders.

\section{Argyris Tzouvelekis*, George Zacharis*, Anastasia} Oikonomou\#, Andreas Koulelidis*, Paschalis Steiropoulos*, Marios Froudarakis*, Pelagia Kriki ${ }^{\natural}$, Vassilios Vargemezis ${ }^{\natural}$ and Demosthenes Bouros*

*Dept of Pneumonology, University Hospital of Alexandroupolis, "Dept of Radiology, University Hospital of Alexandroupolis, and ${ }^{\top}$ Dept of Nephrology, University Hospital of Alexandroupolis, Democritus University of Thrace, Alexandroupolis, Greece.

Correspondence: A. Tzouvelekis, Dept of Pneumonology, University Hospital of Alexandroupolis, Democritus University of Thrace, Alexandroupolis, 68100, Greece. E-mail: atzouvelekis@yahoo.gr

Statement of Interest: None declared.

\section{REFERENCES}

1 Schwarz MI, Brown KK. Small vessel vasculitis of the lung. Thorax 2000; 55: 502-510.

2 Tzelepis GE, Kokosi M, Tzioufas A, et al. Prevalence and outcome of pulmonary fibrosis in microscopic polyangiitis. Eur Respir J 2010; 36: 116-121.

3 Brugiere O, Raffy O, Sleiman C, et al. Progressive obstructive lung disease associated with microscopic polyangiitis. Am J Respir Crit Care Med 1997; 155: 739-742.

4 Schwarz MI, Mortenson RL, Colby TV, et al. Pulmonary capillaritis. The association with progressive irreversible airflow limitation and hyperinflation. Am Rev Respir Dis 1993; 148: 507-511.

5 Cottin V, Nunes H, Brillet PY, et al. Combined pulmonary fibrosis and emphysema: a distinct underrecognised entity. Eur Respir J 2005; 26: 586-593.

6 Cottin V, Le PJ, Prevot G, et al. Pulmonary hypertension in patients with combined pulmonary fibrosis and emphysema syndrome. Eur Respir J 2010; 35: 105-111.

7 Cottin V, Nunes H, Mouthon L, et al. Combined pulmonary fibrosis and emphysema syndrome in connective tissue disease. Arthritis Rheum 2011; 63: 295-304.

8 Churg A, Marshall CV, Sin DD, et al. Late intervention with a myeloperoxidase inhibitor stops progression of experimental COPD. Am J Respir Crit Care Med 2012; 185: 34-43.

9 Guilpain P, Chereau C, Goulvestre C, et al. The oxidation induced by antimyeloperoxidase antibodies triggers fibrosis in microscopic polyangiitis. Eur Respir J 2011; 37: 1503-1513.

DOI: 10.1183/09031936.00216311 